\title{
Análise do acolhimento na estratégia Saúde da Família de Sobral (Ceará): discurso do sujeito coletivo de enfermeiros
}

\author{
Analysis of embracement in Family Health strategy in the city of Sobra (Ceará): \\ discourse of the nurses' collective subject \\ Análisis del acogida en la estrategia Salud de la Familia de Sobral (Ceará): \\ discurso del sujeto colectivo de enfermeros
}
Nara Luana Trajano Aguiar ${ }^{1}$, Marcos Aguiar Ribeiro ${ }^{2(*)}$, Izabelle Mont’Alverne Napoleão Albuquerque $^{3}$, Héryca Laiz Linhares Balica ${ }^{4}$, Nayana Cintia Silveira ${ }^{5}$
${ }^{1}$ Especialista em Gestão da Saúde e Auditoria pela Faculdade Padre Dourado. Enfermeira da Universidade Estadual Vale do Acaraú - Sobral-CE
${ }^{2}$ Mestre em Saúde da Família. Doutorando pelo Programa de Pós-graduação em Enfermagem da Universidade Federal de São Paulo (UNIFESP). Docente do curso de Enfermagem da Universidade Estadual Vale do Acaraú Sobral-CE
${ }^{3}$ Vice-reitora e docente do curso de Enfermagem da Universidade Estadual Vale do Acaraú Sobral-Ceará. Líder do Observatório de Pesquisas para o SUS
${ }^{4}$ Discente do curso de Enfermagem da Universidade Estadual Vale do Acaraú Sobral-CE. Membro do Observatório de Pesquisas para o SUS).
${ }^{5}$ Discente do curso de Enfermagem da Universidade Estadual Vale do Acaraú Sobral-CE. Membro do Observatório de Pesquisas para o SUS

\section{RESUMO}

A Política Nacional de Humanização é composta de diretrizes, dentre elas o acolhimento, que se configura como um dispositivo, fornecendo espaços de escuta e recepção, garantindo o acesso universal e a construção de vínculo. Desse modo, objetiva-se analisar a dinâmica do acolhimento em uma macroárea da Estratégia Saúde da Família do município de Sobral-Ceará, a partir da percepção do enfermeiro. Trata-se de uma pesquisa do tipo exploratório-descritivo com abordagem qualitativa. Os participantes do estudo foram 18 enfermeiros das Unidades Básicas de Saúde do Sistema Municipal. A coleta das informações deu-se por meio de uma entrevista semiestruturada e os dados foram processados por 
meio do Discurso do Sujeito Coletivo. Tem-se, então, o acolhimento como proposta para modificar a logicidade da sistematização e remodelar o trabalho em saúde. O estudo evidenciou que a maioria dos enfermeiros possui conhecimentos a respeito da importância e relevância do acolhimento, contribuindo para uma assistência de qualidade.

Palavras-chave: Acolhimento. Enfermagem. Estratégia Saúde da Família.

\begin{abstract}
The National Humanization Policy consists of guidelines, among which there is the embracement, which is a device providing listening and reception spaces, ensuring universal access and bond building. Thus, this study aims to analyze the dynamics of embracement in a macro area of the Family Health Strategy of the municipality of Sobral, in the state of Ceará, based on the nurses' perception. This is an exploratory-descriptive study with a qualitative approach. The study participants were 18 nurses from the Basic Health Units of the Municipal System. Data collection was done through a semi-structured interview, and data were processed through the Collective Subject Discourse. Embracement is then proposed as a way of modifying the logic of systematization and remodeling health work. The study showed that most nurses know the importance and relevance of the embracement, contributing to quality care.
\end{abstract}

Keywords: User Embracement. Nursing. Family Health Strategy.

\title{
RESUMEN
}

La política nacional de humanización está compuesta por directrices, entre ellas la acogida, que se configura como un dispositivo, y proporciona espacios de escucha y recepción, garantizando el acceso universal y la construcción de vínculo. De este modo, se pretende analizar la dinámica de la acogida en una macroárea de la Estrategia Salud de la Familia de la ciudad de Sobral-Ceará, a partir de la percepción del enfermero. Se trata de una investigación del tipo exploratorio-descriptivo con abordaje cualitativo. Los participantes del estudio fueron 18 enfermeros de las Unidades Básicas de Salud del Sistema Municipal. La recolección de datos se dio a través de una entrevista semiestructurada y los datos fueron procesados por medio del Discurso del Sujeto Colectivo. Se tiene entonces la acogida como propuesta para modificar la logicidad de la sistematización y remodelar el trabajo en salud. El estudio evidenció que la mayoría de los enfermeros poseen conocimientos acerca de la importancia y relevancia de la acogida, interfiriendo en una asistencia de calidad.

Palabras clave: Acogimiento. Enfermería. Estrategia Salud de la Familia.

\section{INTRODUÇÃo}

O Sistema Único de Saúde (SUS) se deu através da institucionalização da lei 8.080 de 19 de setembro de 1990 e pode ser compreendido como uma política de Estado, fruto da materialização de uma decisão adotada pelo Congresso Nacional. Envolve um conjunto organizado e articulado de serviços e ações

de saúde, e une o conjunto das organizações públicas de saúde existentes nos âmbitos municipal, estadual e nacional, e ainda os serviços privados de saúde que o integram funcionalmente para a prestação de serviços aos usuários do sistema, de forma complementar, quando contratados ou conveniados para tal fim¹. 
O artigo 196 da Constituição Federal afirma que "a saúde é direito de todos e dever do Estado". Isso implica que a saúde é um direito e não um serviço a que se tem acesso por meio de uma contribuição ou pagamento de qualquer espécie. Dessa forma, os princípios do SUS expressam a defesa do direito à vida e da igualdade de acesso sem distinção de raça, sexo, religião ou qualquer outra forma de discriminação dos cidadãos brasileiros² .

Frente aos desafios de implementação da consolidação dos princípios do SUS, manifestase a necessidade de mudança para reorganização no modelo de Atenção à Saúde, baseando-se na promoção da saúde e na prevenção de doenças, incentivando o surgimento da Atenção Básica $(A B)^{3}$.

A AB representa um conjunto de ações de saúde, no contexto individual e coletivo, caracterizada pela promoção e proteção da saúde, por meio da prevenção de agravos, diagnósticos, tratamento, reabilitação e manutenção da saúde. As estratégias da $\mathrm{AB}$ são realizadas por meio de práticas gerenciais e sanitárias democráticas e participativas, e considera o sujeito em sua singularidade, na complexidade, na integralidade e na inserção sociocultural, ao mesmo tempo em que busca na promoção da saúde do indivíduo, a prevenção e o tratamento de doenças e a redução de danos ou de sofrimentos. Assim, supõe-se que as tecnologias da $\mathrm{AB}$ devem resolver os problemas de maior frequência e relevância em cada território ${ }^{4}$.

$A \mathrm{AB}$ é o primeiro nível de atenção na organização da rede hierarquizada dos serviços do SUS, e as atividades de saúde ofertadas estão o mais próximo possível do local onde as pessoas vivem e trabalham, possibilitando uma organização no processo de atenção continuada à saúde da população $0^{5}$.

Em 1994, nasce o Programa Saúde da Família, conhecido hoje como Estratégia Saúde da Família (ESF), por não se tratar mais de apenas um programa. É constituído por equipes multiprofissionais responsáveis pela saúde da população ${ }^{6}$. Nessa perspectiva, a $A B$ é vista como porta de entrada preferencial da população no SUS, e é a partir dela que o fluxo por todos os demais setores da saúde deve ser organizado, facilitando no ordenamento da movimentação dentro da rede assistencial. Por isso, nesse primeiro contato, é de suma importância que o usuário possa ser recebido de forma humanizada.

Partindo do princípio da individualidade e subjetividade do ser humano e do protagonismo e responsabilização de todos os envolvidos na produção de saúde - gestores, trabalhadores e usuários - foi criada em 2003, a Política Nacional de Humanização (PNH), com o propósito de sensibilizar e oferecer as mudanças necessárias na perspectiva da atenção à saúde, assegurando aos profissionais e usuários o reconhecimento destes enquanto agentes detentores do poder de transformação e elaboração de práticas em saúde humanizadas ${ }^{7}$.

A PNH é composta de diretrizes, dentre elas o acolhimento, que se configura como um dispositivo, onde fornece espaços de encontro, escuta e recepção que proporcionem a interação entre usuários e trabalhadores, garantindo o acesso universal, a informação, a resolutividade, o encaminhamento para outros serviços referenciados (quando necessário) e a construção de vínculo ${ }^{8}$.

A palavra "acolher" pode obter vários sentidos, evidencia "dar acolhida, aceitar, dar ouvidos, dar crédito a, agasalhar, receber, atender, admitir". O acolhimento compõe-se na humanização das correlações entre profissionais e usuários da saúde, induzindo a modificação do método de organização e o funcionamento do serviço de saúde, provindo de três princípios: atender a todas as pessoas que buscam os serviços de saúde, garantindo a acessibilidade universal; aperfeiçoar o processo de trabalho, deslocando o modelo biomédico para uma equipe multiprofissional; qualificar relação profissional de saúde/usuário a partir de critérios humanitários de solidariedade e de cidadania ${ }^{10}$.

O acolhimento compreende desde a recepção do 
usuário no sistema de saúde e o comprometimento integral de suas necessidades até a atenção resolutiva aos seus problemas. Baseia-se no trabalho centrado nas necessidades dos usuários, na escuta qualificada e na construção de vínculos entre os profissionais e a população, buscando uma postura capaz de acolher e estabelecer respostas mais adequadas. Assim, os usuários precisam ser orientados de maneira adequada, a fim de garantir a continuidade e a eficácia do atendimento ${ }^{11}$.

Portanto, a criação de vínculo é fundamental para promover uma relação de confiança entre trabalhadores e usuários que leve este a aderir às ações de saúde propostas, e envolver no próprio cuidado. Isso ocorre a partir do primeiro momento de encontro entre usuários e trabalhador de saúde, fazendo-se necessárias a afetividade, a ajuda e o respeito para que o serviço em saúde amplie a eficácia das suas ações.

Assim, a partir das vivências práticas ofertadas no decorrer do curso de graduação em Enfermagem, realizadas no campo da $A B$, conduziu a conhecer os fatores facilitadores e restritivos da dinâmica do acolhimento, tendo como enfoque a figura do enfermeiro, de forma a possibilitar a compreensão do acolhimento enquanto estratégia de organização e humanização da assistência no âmbito da AB.

Nessa perspectiva, ao considerar a humanização da assistência como um ato natural, percebe-se que no cotidiano existem diversos desafios na prática do acolhimento. Dessa forma, a pesquisa poderá contribuir para a compreensão do acolhimento como também, na possível qualificação, a partir da sensibilização e estímulo à equipe multiprofissional, através do enfermeiro, visto que esta categoria é a que possui maior contato com os usuários no espaço da UBS. Com isto, haverá a possibilidade de melhorar a qualidade da assistência e a compreensão dos gestores, profissionais e acadêmicos acerca da amplitude e complexidade da práxis do acolhimento.
Desse modo, o estudo tem como objetivo compreender a concepção de acolhimento dos enfermeiros assistenciais e gerentes das UBS, a partir da técnica de análise do Discurso do Sujeito Coletivo.

\section{MÉTODO}

Trata-se de uma pesquisa do tipo exploratóriodescritivo com abordagem qualitativa. O estudo exploratório tem como objetivo proporcionar maior familiaridade com o problema, com vistas a torná-lo mais explícito ou a construir hipóteses ${ }^{19}$. O estudo descritivo realiza a análise, o registro e a interpretação dos fatos do mundo físico sem a interferência do pesquisador ${ }^{20}$.

A abordagem qualitativa responde a questões muito particulares e se ocupa com um nível de realidade que não pode ou não deveria ser quantificado, ou seja, ela trabalha com o universo de significados, motivos, aspirações, crenças, valores e atitudes ${ }^{21}$.

O campo de atuação correspondeu ao Sistema Municipal de Saúde de Sobral. O período de trabalho ocorreu entre os meses de janeiro a março do ano de 2017. O município de Sobral- CE se constitui em uma rede de atenção à saúde hierarquizada e regionalizada com serviços em diferentes níveis de complexidade, fazendo-se polo para a Macrorregião Norte do Ceará. Em relação à $A B$, Sobral conta atualmente com 64 (sessenta e quatro) equipes de ESF, distribuídas em 31 (trinta e uma) UBS. Para melhor organização de estratégias e planejamento, a gestão do município distribui as UBS em macroáreas. Em Sobral, são totalizadas 4 (quatro) macroáreas. Há também, 6 (seis) equipes do Núcleo de Apoio à Saúde da Família (NASF), localizados em áreas compreendidas como territórios, com cobertura assistencial de 98\% da população, o que equivale a 214.206 pessoas acompanhadas. A macroárea 4 (quatro) foi escolhida para a realização do estudo. Conta com a população total de 34.086 habitantes, composta pelas UBS de 
Caioca, Coahb II, Dom Expedito, Patriarca e Sinhá Saboia $^{22}$.

Justifica-se a escolha da macroárea 4 (quatro) pelo fato de ser composta por UBS tanto na sede do município quanto em distritos, no qual é possível obter análise de duas realidades distintas com demandas diferentes, alcançando maior compreensão do estudo.

Os participantes do estudo foram 18 (dezoito) enfermeiros sendo 13 (treze) assistenciais e 5 (cinco) gerentes das 5 (cinco) UBS constituintes da macroárea 4 (quatro), visto que na ESF é primordial a figura do enfermeiro na construção da equipe básica multidisciplinar, o que tem demonstrado um espaço de progresso, reconhecimento e autonomia deste profissional. A presença do enfermeiro representa um membro dinâmico no processo de fortalecimento da ESF, de modo a vivenciar de forma intensa o acolhimento como política de humanização da saúde. Dessa forma, é fundamental conhecer a opinião dos enfermeiros diante da prática do acolhimento ${ }^{23}$.

Constituíram-se como critérios de inclusão: ser enfermeiro da ESF; aceitar participar do estudo; ter no mínimo seis meses de experiência na ESF, visto que este período é considerado um tempo razoável para vivenciar o cotidiano na ESF, de forma a colaborar e dar subsídios para a pesquisa. Como critérios de exclusão: ter menos de seis meses de experiência na ESF.

A coleta das informações acerca do objeto em estudo se deu por meio de uma entrevista semiestruturada, em que pode ser entendida como uma estratégia de alcance de informações, que presume um diálogo constante incluindo entrevistado e entrevistador, permitindo ao entrevistador conduzir a conversa baseando-se em seus fins ${ }^{24}$. Além disto, na entrevista semiestruturada, o entrevistador torna-se apto em guiar o diálogo naturalmente e seguir adiante, nas direções que considerar necessário. Dessa maneira, o entrevistador poderá obter uma ampla visão do assunto em questão. Comumente, as questões são abertas e viabilizam respostas que se encaixam no interior de um diálogo descontraído e são perfeitamente consideráveis partindo deste princípio ${ }^{25}$.

Após a seleção dos participantes do estudo, de acordo com os critérios de inclusão, estes foram questionados quanto ao melhor local para realização da entrevista, visando a necessidade e disponibilidade dos mesmos. Salienta-se que a entrevista foi gravada conforme autorização de cada um dos participantes do estudo.

Após a coleta, as informações foram processadas por meio da técnica de análise do Discurso do Sujeito Coletivo (DSC), em que consiste na tabulação e sistematização de informações qualitativas de caráter verbal, sendo possível retirar as Ideias Centrais (IC) e suas Expressões Chave (ECH) adequadas. O DSC é um discurso-síntese composto por partes de discursos de significados semelhantes, mediante estratégias organizadas e normatizadas. Desse modo, a fala expressa nos depoimentos não foram inválidas. O que de fato acontece é a reconstrução em fragmentos de discursos próprios, até onde considerar necessário, para que se estabeleça um ponto de vista ou representação social sobre um determinado acontecimento ${ }^{26}$.

Assim, o DSC retrata uma transformação dentro das pesquisas qualitativas por possibilitar a compreensão de ideias, opiniões, valores e princípios em comum do coletivo, a respeito de um determinado assunto, empregando técnicas científicas ${ }^{27}$.

Para que as respostas fossem metodologicamente tratadas e analisadas, utilizou-se os recursos do programa QualiQuantSoft. Este software possui embasamento na teoria do DSC, criado com a finalidade de alcançar o pensamento coletivo, onde facilitará no manuseio da técnica do DSC. O procedimento consiste fundamentalmente na análise do conteúdo verbal apurado, retirando de cada um dos depoimentos as IC e suas respectivas ECH. A formulação de IC e ECH semelhantes permite a determinação de um ou múltiplos DSC ${ }^{26}$. 
Para melhor compreensão do processo de análise das informações no DSC, de acordo com Lefèvre e Lefèvre $^{26}$, dividide-se em etapas:

1a etapa: Reprodução fiel dos dados colhidos por meio do instrumento utilizado;

$2^{\mathbf{a}}$ etapa: Com zelo, haverá nesta etapa a interpretação do material reproduzido, apresentando a integralidade das respostas de cada um dos participantes e em seguida, cada resposta será analisada isoladamente conforme a pergunta;

$3^{\mathbf{a}}$ etapa: Transcrição total de todas as respostas dos participantes no mecanismo de Análise de Discurso 1 (IAD1), mostrando as ECH. A partir da propriedade das ECH, seguindo com a interpretação de cada uma destas, será detectada IC;

4 $\mathbf{a}^{\mathbf{a}}$ etapa: $\mathrm{Na}$ última etapa, haverá a preparação do Instrumento de Análise do Discurso 2 (IAD2), seguindo com a produção da Síntese das Ideias Centrais (SIC) com seu DSC específico.

Este estudo obteve parecer favorável da Comissão Científica da Prefeitura Municipal de Sobral e do Comitê de Ética em Pesquisa da Universidade Estadual Vale do Acaraú no mês de dezembro do ano de 2016, com número de parecer: 1.875.844, sendo orientado pela Resolução de № 466, de 12 de dezembro de 2012, do Conselho Nacional de Saúde, em que incorpora, sob a ótica do indivíduo e das coletividades, os quatro referenciais básicos da bioética: autonomia, não maleficência, beneficência e justiça, entre outros, e visa assegurar os direitos e deveres que dizem respeito aos participantes da pesquisa, à comunidade científica e ao Estado ${ }^{28}$.

Assim, os pesquisadores participantes do estudo, comprometeram-se em reduzir os riscos aos participantes buscando o cuidado na elaboração de questões no que concerne à realização de uma entrevista semiestruturada, sem provocar constrangimento aos participantes da pesquisa.

Os participantes do estudo foram esclarecidos sobre os objetivos da pesquisa, de forma a autorizar sua participação, a partir da assinatura do Termo de Consentimento Livre e Esclarecido (TCLE).

\section{RESULTADOS}

No que concerne ao perfil dos participantes do estudo, obteve-se 18 (dezoito) enfermeiros da ESF entrevistados, sendo 5 (cinco) enfermeiros gerentes e 13 (treze) enfermeiros da assistência. O período de atuação na ESF dos enfermeiros entrevistados variou entre 8 (oito) meses e 9 (nove) anos.

Quando questionados acerca da compreensão do termo acolhimento na ESF, surgiram opiniões divergentes entre os enfermeiros entrevistados. Assim, observou-se que as respostas para esta IC proporcionaram a construção de dois DSC distintos (DSC “A” e DSC “B”). Elabora-se o DSC "A", cujas respostas foram evidenciadas de acordo com a definição de acolhimento conforme preconiza o MS através da PNH:

O Acolhimento, como o próprio nome já diz, é a forma que você acolhe, de modo que essa atenção aconteça humanizada. É receber, atentar, ouvir, informar, tornar o paciente familiar ao ambiente que ele está chegando, no caso o CSF. É o jeito de como o paciente se sente recepcionado, e como nós, enfermeiros e também os demais profissionais da saúde, damos respostas às necessidades que eles nos trazem. Não só o enfermeiro, mas qualquer outro profissional ou trabalhador da saúde que atue na UBS tem o dever e obrigação em estar acolhendo o usuário. O profissional acolhe dando informações que o paciente esteja precisando e direcionando-o para os locais corretos onde possam atender suas necessidades, oferecendo orientações sobre o fluxo do serviço. Aqui na unidade, ocorre desde o momento que o usuário adentra ao CSF, percorrendo por toda a unidade. Acontece o encontro do paciente com qualquer profissional ou trabalhador da saúde, começando na porta de entrada da UBS, iniciando geralmente com o porteiro, cujo é o primeiro contato do paciente no CSF. Assim, é importante que toda a equipe de saúde esteja instruída de como deve abordar os usuários, no qual essa abordagem deve ser de forma 
branda e paciente, seja ouvindo, oferecendo orientações ou tirando algumas dúvidas trazidas pelos pacientes. Já que acolher não se configura apenas em realizar uma consulta propriamente dita, vai muito além disso. É fazer uma escuta qualificada, é ter diálogo, é saber por qual motivo o paciente busca o CSF. O acolhimento é uma ferramenta muito importante, pois é visto como o condutor das ações de toda a equipe de saúde do CSF e assim o cuidado pode ser norteado. Muitas vezes o acolhimento é confundido, na atenção primária, com o processo de triagem, cujo são métodos diferentes. Qualquer assistência que realizamos, seja triagem ou não, qualquer abordagem que o paciente venha buscar ajuda dentro ou até mesmo fora da UBS, na minha concepção, é dito como acolhimento (DSC A).

O momento da triagem também foi colocado por alguns enfermeiros como acolhimento. Evidenciase que as respostas proporcionaram a construção do DSC "B":

O acolhimento é quando o profissional realiza a classificação de risco dos pacientes, diferenciando o grau de necessidade de atendimento e o grau de prioridade. Aqui na UBS acontece como se fosse uma triagem, cujo é uma consulta. O profissional atende o paciente, observa a queixa apresentada e se o enfermeiro tiver o poder de resolutividade para aquele caso, já resolve logo ou, caso contrário, agenda ou encaminha. Se for algo de urgência, encaminha para algum serviço de urgência e emergência enfim, faz os encaminhamentos necessários. Muitas vezes, os pacientes não têm paciência de esperar, querem passar uma na frente dos outros, e a gente explica que existem pessoas com necessidades mais urgentes, mas muitas pessoas não entendem isso (DSC B).

Quando indagados quanto aos aspectos positivos do acolhimento realizado na ESF, verifica-se que as respostas proporcionaram a construção do DSC "C":

É impossível fazer atenção básica de qualidade sem realizar o acolhimento, pois ele permeia todo o nosso fazer. Pra mim, a importância do acolhimento é o que ele significa e isso eu vejo como um fator positivo. É fazer com que eu me aproxime do usuário, é fazer com que eu consiga enxergar o paciente além da queixa clínica, é o que tem por trás daquela queixa, e indicar a possivel solução do problema. É o profissional chamar pelo nome, é realmente tratar o paciente com empatia. Então pra mim, o acolhimento é fundamental, sem ele eu nem sei como que dá para fazer atenção primária. É através do acolhimento que realizamos melhores direcionamentos. O vínculo criado entre o usuário e o profissional é outro aspecto positivo. O usuário tem a possibilidade de ampliar sua visão e esquecer um pouco do modelo medicalocêntrico, ele percebe que outros profissionais do CSF podem estar contribuindo com estratégias para suprir as suas necessidades apresentadas, conseguem uma boa relação com os profissionais, já existindo aquela confiança, já sabendo a quem dirigir-se para dialogar, tirar dúvidas, conhecem um pouco do fluxo do atendimento. E isso também contribui tanto para a promoção da saúde, para que o paciente se responsabilize pela sua condição de saúde, quanto para deixar a população a par dos serviços que a UBS dispõe. Alguns pacientes nós já conquistamos através da educação em saúde, mostrando de que maneira acontece essa organização do serviço. Aqui na UBS estamos sempre trabalhando isso, com toda a equipe. Acredito que todos estão empenhados em acolher de forma humana os usuários, pois esperamos que estes possam sair satisfeitos com o serviço prestado pelo CSF. Esse é um desafio diário, mas nós temos essa preocupação (DSC C).

É possível identificar também nos discursos, que alguns dos enfermeiros destacam a questão do vínculo estabelecido por meio de atos simples como dar boas-vindas, conhecendo-os, chamando-os pelos seus nomes e mantendo bom relacionamento entre profissionais e usuários.

Quando questionados acerca das limitações ou dificuldades da prática do acolhimento na ESF, verifica-se que as respostas proporcionaram a construção do DSC "D”:

A dificuldade é que ainda existem alguns profissionais que não dão tanta importância ao processo do acolhimento, não conseguem enxergam o quão valioso é este momento. Este é um ponto que é levado em consideração nos momentos de roda, quando todos os funcionários do CSF estão reunidos, visto que é uma maneira de sensibilizar a equipe de saúde, onde todos os profissionais da UBS são responsáveis por acolher de forma humana os pacientes, e que a equipe precisa trabalhar em uma só voz, em união. Acontece também que na maioria das vezes a demanda de atividades do CSF é muito grande, impedindo que 
o acolhimento aconteça realmente da maneira que o usuário merece. A rotatividade dos profissionais também afeta um pouco na continuidade desse cuidado. Outra limitação que vejo é por parte dos usuários, pois há uma dificuldade na compreensão destes em entender de como o serviço da unidade é organizado. Porém, temos que ter em mente que nada pode impedir com que aconteça um recebimento de forma humanizada na UBS, afinal, isso diz muito sobre a maneira como trabalhamos (DSC D).

Ao indagar sobre possíveis sugestões para melhoria da prática do acolhimento na ESF, observa-se que as respostas proporcionaram a construção do DSC "E":

É trabalhar mais com educação em saúde tanto com a população como também com os profissionais acerca da importância do processo do acolhimento. É sensibilizar o profissional de como ele deve acolher, receber os usuário no CSF, pois é notório que alguns profissionais ainda não têm essa noção do verdadeiro significado de acolher. É fortalecer os nossos recursos humanos, na perspectiva de realmente trabalhar com zelo e atenção aos usuários. Precisamos melhorar a nossa escuta, direcionar melhor esse paciente, para que assim possamos identificar os fatores de riscos e consequentemente mostrar as soluções adequadas. Vejo como um serviço de "formiguinha". É todo dia conquistar um pouco, com união, é claro. Não ter preguiça de orientar a mesma coisa se mil vezes for preciso, não se deter em explicar que nem sempre aquela ideia formada que o paciente traz para a unidade é a melhor solução para aquele problema. É um trabalho lento, de bater todos os dias na mesma tecla, mas eu vejo como o único caminho: trabalhar com educação em saúde. É orientar. Dar mais trabalho sim, cansa mais, mas acho que ao longo prazo o resultado é positivo. O importante é não desistirmos. Enfim, é extremamente necessário que haja o acolhimento (DSC E).

\section{DISCUSSÃo}

Ao analisar os discursos, percebe-se que a maioria dos enfermeiros entrevistados compreende e mostra familiaridade a respeito da definição de acolhimento como é descrito na $\mathrm{PNH}$.

O acolhimento é uma proposta que visa o aperfeiçoamento das relações que integram os serviços de saúde com os usuários. O MS prioriza, com a execução da PNH, uma assistência de qualidade em que possa haver a atuação integrada de gestores, trabalhadores e usuários na solidificação do SUS. Nesta situação, pode-se dizer que há a concretização do acolhimento, a partir do instante em que o usuário, espontaneamente, entra de alguma forma em contato com os profissionais de saúde do $\mathrm{CSF}$, e que neste momento exista a possibilidade em realizar uma escuta qualificada das necessidades apresentadas pelo usuário, evidenciando possíveis soluções $^{29}$.

O acolhimento está fundamentado também em um direito constitucional dos indivíduos, no qual é permitido o privilégio de acesso aos serviços de saúde do SUS. Visto que a AB é dita como porta de entrada desse sistema, para tornar-se efetiva é necessária a utilização de um mecanismo facilitador que possibilite o fluxo da população nas ações de saúde, tornando-se indispensável o uso de metodologias institucionais e profissionais que atuem como práticas simplificadoras desse acesso ${ }^{30}$.

A maioria dos enfermeiros participantes do estudo entende que o acolhimento deve ser praticado por todos os trabalhadores do CSF e que o usuário deve ser acolhido em todos os locais da UBS, representando a correta percepção de que embora o primeiro contato seja um fator estratégico para o início da relação entre usuário-profissional, o acolhimento não deve encerrar neste momento.

Muitos profissionais continuam a caracterizar o acolhimento como uma triagem. Porém, este não deve ser simplificado à priorização dos casos, 
transfigurado exclusivamente em um processo com a finalidade de classificar o indivíduo quanto ao risco clínico e deixá-lo em ordem de atendimento, de forma mecanicista, mas sim a uma escuta mais ampla que aquele atendimento pontual num momento de urgência e resolução de problema ${ }^{15}$.

Nessa perspectiva, percebe-se que alguns enfermeiros entrevistados ainda não compreendem a definição de acolhimento na sua ampla significância. Isso está diretamente relacionado com algumas barreiras encontradas no cotidiano pelas equipes de saúde da família e afetam na qualidade da assistência prestada pelos enfermeiros e por outros profissionais de saúde. Desse modo, os usuários não se sentem acolhidos ou satisfeitos com o atendimento prestado pela equipe do CSF. Porém, esses desafios podem ser minimizados a partir do momento em que um acolhimento de qualidade passa a ser desenvolvido pelos profissionais ${ }^{31}$.

Com base na análise dos discursos, constatase que os enfermeiros percebem a contribuição do acolhimento diante das atividades cotidianas na ESF e consideram importante que exista um direcionamento de como, quando e quais pessoas devem acolher o usuário.

No Brasil, a ideia de acolhimento propõe maneiras de atenção à demanda espontânea, sem deter-se muito à consulta médica, mas sim preocupandose em promover ligações entre as necessidades expostas pelos usuários e as diversas possibilidades de intervenções no cuidado. Desse modo, surgiu a ideia de incluir no processo de cuidado e atenção às diversas categorias profissionais da saúde, a fim de retirar a figura do médico como protagonista do cuidado, envolvendo outras abordagens e instruções possíveis, que não sejam apenas biomédicas para as enfermidades e outras demandas ${ }^{32}$.

Dessa forma, é necessário que o profissional realize simultaneamente: a acolhida e a escuta qualificada e de forma individual, discutindo os problemas apresentados pelo usuário; estabelecer uma avaliação de riscos associando às vulnerabilidades que o indivíduo esteja exposto; mobilizar os demais integrantes da equipe responsáveis pelo cuidado daquele paciente para discutir e avaliar as possíveis soluções da problemática evidenciada. Para que tudo isso suceda, é fundamental a prática profissional com importante qualidade de comunicação, interpretação e negociação interdisciplinar envolvendo também o usuário, a fim de estimular o vínculo, buscar soluções e minimizar ansiedades ${ }^{29}$.

Embora com todas as dificuldades que impedem a execução do acolhimento, os enfermeiros participantes do estudo mostraram-se dispostos a tratar os pacientes de forma mais humanizada. A relevância do vínculo entre usuário e a equipe de saúde é destacada por meio da atribuição de responsabilidades adquiridas pelos profissionais, tornando-se possível a promoção da autonomia dos usuários, a partir da construção de um novo modo de agir na produção do cuidado ${ }^{30}$.

Esses argumentos dizem respeito à importância de estimular no profissional de saúde a responsabilização pelo cuidado prestado durante um bom serviço de acolhimento, fornecendo atenção integral, escutando as necessidades dos usuários com empatia e vínculo bem estabelecidos. ${ }^{33}$

Apesar de a maioria dos enfermeiros entrevistados se considerarem acolhedores, diante da interpretação dos discursos, ficaram evidentes as dificuldades para a prática do acolhimento. Dentre essas, destacase a sobrecarga de trabalho e certa rotatividade dos profissionais contratados que, geralmente, permanecem no serviço por um tempo determinado, prejudicando a continuidade do cuidado e a construção do vínculo.

Observa-se, a partir das percepções dos enfermeiros, que a maioria dos usuários não compreende as verdadeiras competências de uma UBS, confundindoas com serviço de pronto atendimento, buscando uma solução imediata para suas necessidades. Esse pensamento imediatista não vai ao encontro dos 
interesses da AP o que afeta e prejudica a relação entre profissionais e usuários ${ }^{4}$.

O MS recomenda a realização de educação permanente envolvendo a $\mathrm{PNH}$, indicando-a que, além de ser incluída como componente profissionalizante na graduação, pós-graduação e extensão em saúde, possa orientar também processos de educação permanente em saúde aos trabalhadores nos próprios serviços de saúde ${ }^{34}$. No entanto, ao analisar as entrevistas, notou-se que os enfermeiros ingressam na ESF sem a adequada orientação ou qualificação quanto às diretrizes da PNH.

Dessa forma, os próprios enfermeiros do serviço relatam a importância da educação permanente em saúde relacionada à $\mathrm{PNH}$ a qual envolve a maneira como o profissional deve acolher o usuário e ressaltam a necessidade de qualificações das equipes de saúde por meio de estratégias educativas.

Em suma, a diretriz operacional do acolhimento surge dos seguintes princípios: atender a todas as pessoas que procuram os serviços de saúde, garantindo acessibilidade universal, criando possibilidades para o estabelecimento de vínculo, responsabilização e resolutividade dos problemas de saúde; reorganizar o processo de trabalho, de forma que este desloque seu eixo central da escuta do usuário, comprometendose a resolver seus problemas de saúde; qualificar a relação trabalhador-usuário, que deve se dar por fatores humanitários de solidariedade e cidadania ${ }^{35}$.

Tem-se, então, o acolhimento como proposta fundamental para modificar a logicidade da sistematização e funcionamento dos serviços de saúde e remodelar o processo de trabalho em saúde.

\section{CONCLUSÕES}

Pode-se dizer que o acolhimento é uma estratégia de organização da equipe de saúde que assegura a inclusão do usuário e oportuniza um trabalho voltado à integralidade da atenção de maneira sistemática ao prezar as condições de saúde da população.
Consolidar o vínculo entre profissionais e usuários colabora para a existência de um exercício com abrangência multidisciplinar de modo a interferir nas mudanças das relações de trabalho.

O estudo evidenciou que a maioria dos enfermeiros entrevistados possui conhecimentos a respeito da importância e relevância do acolhimento, de modo que dependendo da maneira de como este seja praticado, interfere negativamente ou positivamente para uma assistência de qualidade na ESF. Porém, há uma minoria que ainda desconhece a natureza do legítimo conceito de acolhimento.

Discutir o acolhimento com o propósito de acolhida, escuta qualificada e direcionamento das ações respeitando a equidade e a integralidade dos sujeitos, implica-se em um importante fato para que este possa ir muito além de uma triagem ou classificação de risco. Ao pensar nessas particularidades, é evidente que o acolhimento ultrapassa as características do atendimento e passa a ser compreendido, em sua essência, como uma postura dependendo única e exclusivamente da organização do sistema e dedicação dos profissionais.

Desse modo, é essencial que o acolhimento esteja presente em todos os momentos de encontro com outra pessoa. Para tal fim, é preciso que os profissionais demonstrem interesse pela fala do usuário, o que propiciará o fortalecimento do vínculo e credibilidade nas propostas de intervenções no cuidado em saúde. Trabalhar com o acolhimento humanizado favorece a criação de ligações positivas entre a comunidade que busca a resolubilidade de suas necessidades de saúde e a equipe de profissionais que trabalham em prol da satisfação do usuário.

Destaca-se também que, embora haja certa rotatividade de enfermeiros nos CSF, os profissionais empenham-se para que o vínculo entre usuárioprofissional se restabeleça e, assim, obter maior proximidade e de alguma forma o acolhimento é facilitado. 
Deve-se considerar que não se pode resumir o acolhimento apenas à construção de vínculo e à acessibilidade da população aos serviços de saúde, já que isto pode ocorrer a qualquer momento, não havendo a necessidade do vínculo construído ou acesso garantido. Contudo, sempre que o acolhimento é exercido com qualidade, involuntariamente o vínculo e o acesso são efetivados de modo a repercutir em resultados positivos na assistência dos usuários.

Atentar-se também às sugestões propostas pelos enfermeiros entrevistados em relação à prática de educação permanente em saúde, como é preconizado pelo MS acerca desse tema, a profissionais que adentram à ESF poderá ser uma estratégia de intervenção e quem sabe ser algo que possa influenciar positivamente para a melhoria da qualidade da assistência no município onde o estudo foi realizado, visto que as falhas na gestão em saúde prejudicam a execução das funções dos profissionais, além de influenciar negativamente a relação destes com os usuários.

Percebe-se que o acolhimento não é um espaço ou um local, mas sim uma postura ética. Não presume a profissional específico para realizá-lo, provoca compartilhamento de saberes, angústias e concepções. De maneira geral, espera-se que o acolhimento e o cuidado absoluto totalizando a integralidade do indivíduo possam ser melhores discutidos e articulados, referindo-se ao município onde o estudo foi realizado, para que haja melhores condições de acesso, organização, humanização e assistência integral.

Almeja-se, minimizar as falhas que a ESF e a gestão municipal encontram, para que autênticas transformações possam suceder, proporcionando, assim, melhor qualidade de vida para a população local. É necessário que os profissionais trabalhem em equipe de maneira uniforme, com objetivos comuns e identifiquem obstáculos que interfiram nos planos de intervenções associados com a integralidade da atenção à saúde. O sucesso do acolhimento está inteiramente relacionado aos profissionais que sabem respeitar as diferentes demandas da população atendida e assisti-la com integralidade.

\section{REFERÊNCIAS}

1. Brasil. Lei n. 8.080 de 19 de setembro de 1990. Dispõe sobre as condições para a promoção, proteção e recuperação da saúde, a organização e o funcionamento dos serviços correspondentes, e dá outras providências. Diário Oficial da União, Brasília, DF, 20 set. 1990.

2. Brasil. Constituição (1988). Constituição da República Federativa do Brasil. Brasília, DF: Senado Federal; 1988. Art 196

3. Rocha BS, Munari RDB, Bezerra ALQ, Melo LKA. Enfermeiros Coordenadores de Equipe do Programa Saúde da Família: perfil profissional. Rev de Enferm, 2009; 17(2), 229233

4. Ministério da Saúde (BR). Política Nacional de Atenção Básica. Brasília: Ministério da Saúde; 2006.

5. Gomes FM, Silva MGC. Programa Saúde da Família como estratégia de atenção primária: uma realidade em Juazeiro do Norte. Ciênc Saúde Coletiva, 2011; 16(1), 893-902.

6. Ramos LA. Acolhimento: uma forma de organização do trabalho em saúde. Núcleo de Educação em Saúde Coletiva. Várzea da Palma; 2010.

7. Ministério da Saúde (BR). Secretaria de Atenção à Saúde. Núcleo Técnico da Política Nacional de Humanização: a humanização como eixo norteador das práticas de atenção e gestão em todas as instâncias do SUS. Brasília: Ministério da Saúde; 2004

8. Fracolli LA, Zoboli, ELP. Acolhimento: uma tecnologia para a assistência. A enfermagem na gestão em atenção primária à saúde. 1 ed. Barueri, SP: Manole. 2007. 376-392.

9. Ferreira $\mathrm{ABH}$. Novo Dicionário Aurélio Língua Portuguesa. Rio de Janeiro, 2008

10. Baião BS, Oliveira RA, Lima VVPC, Matos MV, Alves KAP. Acolhimento humanizado em um posto de saúde urbano do Distrito Federal, Brasil. Rev. APS.2014;17(3): 291-302.

11. Ministério da Saúde (BR). Acolhimento com avaliação e classificação de risco. Brasília: Ministério da Saúde; 2004.

12. Ministério da Saúde (BR). Núcleo Técnico da Política Nacional de Humanização. Brasília: Ministério da Saúde; 2010, 4 ed.

13. Ministério da Saúde (BR). Política Nacional de Humanização. Brasília: Ministério da Saúde; 1 ed. 2013.

14. Ministério da Saúde (BR). Secretaria de Atenção à Saúde. Núcleo Técnico da Política de Humanização. HumanizasUS: documento base para gestores e trabalhadores do SUS. Brasília: Ministério da Saúde; 4.ed. 2008. 
15. Souza ECF, Vilar RLA, Rocha NSPD, Uchoa AC, Rocha PM. Acesso e acolhimento na atenção básica: uma análise da percepção dos usuários e profissionais de saúde. Cad Saúde Pública,2008. (24)

16. Ministério da Saúde (BR). Secretaria de Atenção à Saúde. Núcleo Técnico da Política Nacional de Humanização: a humanização como eixo norteador das práticas de atenção e gestão em todas as instâncias do SUS. Brasília: Ministério da Saúde; 2004.

17. Londero S. Reinventando o acolhimento em um serviço de saúde mental. Instituto de Psicologia. Porto Alegre; 2010

18. Ministério da Saúde (BR). Núcleo Técnico da Política Nacional de Humanização. Acolhimento nas práticas de produção de saúde. Secretaria de Atenção à Saúde Brasília: Ministério da Saúde; 2ed. 2006.

19. Gil AC. Como elaborar Projetos de Pesquisa. 4 ed. São Paulo: Atlas; 2002.

20. Barros AJS, Lehfeld NAS. Fundamentos de metodologia científica. 3.ed. São Paulo; Pearson Prentice Hall, 2007.

21. Minayo MCS. Pesquisa Social. Petrópolis; 2007.

22. Sobral. Vigilância Epidemiológica. Dados da Atenção Básica à Saúde. Sobral, 2015.

23. Silva VG, Motta MCS, Zeitoune RCG. A prática do enfermeiro na Estratégia Saúde da Família: o caso do município de Vitória/ES. Rev Eletr Enf, 2013;12(3), 441-448.

24. Ludkiewicz HFF. Processo para a tomada de decisão estratégica: um estudo de caso na parceria banco e varejista, 2008.

25. Lakatos EM, Marconi MA. Fundamentos de metodologia científica. 5 ed. São Paulo: Atlas; 2003.

26. Lefevre F, Lefevre AMC. O Discurso do Sujeito Coletivo: um novo enfoque em pesquisa qualitativa. Caxias do Sul: Educs; 2003.

27. Figueiredo MZA, Chiari MB, Goulart BNG. Discurso do Sujeito Coletivo: uma breve introdução à ferramenta de pesquisa qualiquantitativa. Distúrb Comun, 2013; 25(1), 129136.
28. Ministério da Saúde (BR). Conselho Nacional de Saúde. Resolução № 466, de 12 de dezembro de 2012. Dispõe sobre pesquisas envolvendo seres humanos. Brasília: Ministério da Saúde, 2012.

29. Tesser CD, Neto PP, Campos GWS. Acolhimento e (des) medicalização social: um desafio para as equipes de saúde da família. Ciência e Saúde Colet,2010;15(3), 3615-3624.

30. Franco TB, Bueno WS, Merhy EE. Acolhimento e os processos de trabalho em saúde: o caso de Betim/MG. Cad Saúde Pública.1999; 15(2),345-353.

31. Viegas SMF, Penna CMM. O vínculo como diretriz para a construção da integralidade na Estratégia Saúde da Família. Rev Rede Enferm Nordeste, 2012; 13(2), 375-385.

32. Guardini R. Ética do Acolhimento. Revista THOT, 2002; 63-69.

33. Merhy EE. A rede básica como uma construção da saúde pública e seus dilemas. São Paulo: Hucitec, 1997.

34. Ministério da Saúde (BR). HumanizaSUS: Ambiência. Brasília: Ministério da Saúde, 2010.

35. Merhy EE, Junior HMM, Rimoli J, Franco TB, Bueno WS. O trabalho em saúde: olhando e experienciando o SUS no cotidiano. $2^{\underline{a}}$ ed. São Paulo: Hucitec, 2004.. 